\title{
Electron Paramagnetic Resonance Study of the Fractions and Trapped Compounds in Asphaltenes of Merey Heavy Crude Oils and Its Vacuum Residue
}

\author{
Maury S. Hernández and Pedro J. Silva* \\ Cite This: https://dx.doi.org/10.1021/acs.energyfuels.0c00254 \\ Read Online
}

ACCESS |

山ll Metrics \& More

Article Recommendations

Supporting Information

ABSTRACT: The electron paramagnetic resonance (EPR) technique was used to study the behavior of the asphaltenes from the Merey crude oil (ASCM), its vacuum residue (ARVM), its fractions, and trapped compounds ( $A_{1}$-ASCM, $A_{2}$-ASCM, TC-ASCM, $A_{1}$-ARVM, $A_{2}$-ARVM, and TC-ARVM). Asphaltenes were precipitated from Merey heavy crude oil and its vacuum residue. The fractionation of our petroleum asphaltenes was carried out using the para-nitrophenol (PNP) method. Two fractions named $\mathrm{A}_{1}$ and $\mathrm{A}_{2}$ and trapped compounds were obtained. The temperature dependence of the EPR spectra was used to obtain a set of temperatures related to free radical (FR) generation and recombination. From the analysis of the EPR spectrum of the most intense signal of the vanadium, we obtain the temperature ranges of the anisotropic-to-isotropic domains, we found a nonlinear behavior of the $\mathrm{B}$ parameter in the temperature range studied, and we propose a functional relationship for this parameter as a function of the temperature. On the other hand, we found the temperatures for the slow-to-fast motion regime in these samples and correlated it with the mobility of the fractions.

\section{INTRODUCTION}

The trapped free-radical (FR) is proposed as a host-guest complex to explain free radicals in asphaltene molecules. ${ }^{1,2}$ In general, carbon free radicals are exceedingly reactive species, which are not expected to survive when they are exposed. Thus, these species should be effectively isolated from the environment by being trapped or caged in asphaltene traps. This idea could be extended to any compound that could play a guest role. ${ }^{3}$ As it was suggested, ${ }^{2}$ this kind of complex could account for the failure to extract all metallic porphyrins from asphaltenes. ${ }^{4}$ The presence of free radicals in asphaltenes, detected long ago, ${ }^{5,6}$ is a very intriguing fact. This is because these radicals are among the most reactive species in organic chemistry, and to our knowledge, a radical such as the one expected in this case (polycyclic aromatic), has never been isolated in pure form. As suggested in the above-referred work, ${ }^{1}$ the survival of free radicals would be possible by the shielding provided by other aromatic compounds in the aggregate. In this way, the free radical will remain "caged" and preserved against chemical reactions. ${ }^{2}$

Although crude oils studied by us ${ }^{7}$ have been subjected to thermal and distillation treatments, free radicals persist; it could be interesting to fractionate the samples obtained from the distillation processes and their vacuum residues to evaluate the behavior of the free radicals in these terms. It is desirable to determine if fractionation can expose free radicals from asphaltenes samples, or if on the contrary, it is necessary to apply more aggressive processes to be able to strip them. This information could shed light on the role played by free radicals in the aggregation processes of asphaltenes. In our electron paramagnetic resonance (EPR) study on asphaltenes of heavy and extra-heavy crude oils, ${ }^{7}$ the Merey heavy crude oil asphaltenes, labeled as ASCM, and their vacuum residue asphaltenes, labeled as ARVM, who have the highest values of API gravity $\left(16^{\circ} \mathrm{API}\right.$ and $3.3^{\circ} \mathrm{API}$, respectively) of all samples studied, showed the highest spin density concentration (ASCM highest between crude oils asphaltenes, and ARVM lowest between vacuum residues asphaltenes and highest than ASCM). However, one would expect the free radical content in the asphaltenes to be maintained even when the vacuum residues to crude oils ratio changes, maintaining similar tendencies in all the samples, but this has not happened, on the contrary, the free radical content of asphaltenes from Merey vacuum residue was considerably smaller than the rest of vacuum residue samples; also, the temperature dependence of the EPR line intensity of free radicals from ASCM showed the highest valley $\left(\mathrm{Tv}_{1}\right)$ and cusp $\left(\mathrm{Tc}_{2}\right)$ temperatures in comparison with the rest of samples. It is worthwhile to point out that Merey heavy crude oil is the result of a blend of two crude oils: $32.8 \%$ Mesa 30 light crude oil and 61.8\% extraheavy crude oil which could be Carabobo or Hamaca. ${ }^{8}$ This mixture of crude oils makes it even more interesting to carry out an exhausting study of asphaltenes from Merey heavy crude oils and their vacuum residues.

The fractionation of our petroleum asphaltenes was carried out using the para-nitrophenol (PNP) method proposed by Acevedo et al. ${ }^{9,10}$ It was proposed that asphaltene colloids in

Received: January 23, 2020

Revised: $\quad$ March 19, 2020

Published: March 30, 2020 
Table 1. FR and $\mathrm{V}^{+4}$ Concentration and Line Widths of Studied Samples

\begin{tabular}{|c|c|c|c|c|c|c|}
\hline sample & label & $\begin{array}{c}\text { concentration of FR in asphaltenes, } \\
\text { spin } / \mathrm{g}\left(\times 10^{19}\right)\end{array}$ & $\begin{array}{c}\text { concentration of } \mathrm{V}^{+4} \text { in asphaltenes, } \\
\text { spin } / \mathrm{g}\left(\times 10^{19}\right)\end{array}$ & $\begin{array}{l}\text { relation }[\mathrm{FR}] / \\
{\left[\mathrm{V}^{4}\right]}\end{array}$ & $\begin{array}{l}\Delta H_{\mathrm{pp}}[\mathrm{G}] \\
\quad \text { of } F R\end{array}$ & $\begin{array}{l}\Delta H_{\mathrm{pp}}[\mathrm{G}] \\
\text { of } \mathrm{V}^{+4}\end{array}$ \\
\hline $\begin{array}{l}\text { Merey crude oil } \\
\text { (heavy) }\end{array}$ & ASCM & 1.311 & 6.9 & 0.190 & 6.3 & 12.5 \\
\hline $\mathrm{A}_{1}$ fraction of ASCM & $\begin{array}{l}\mathrm{A}_{1^{-}} \\
\mathrm{ASCM}\end{array}$ & 1.222 & 7.8 & 0.157 & 6.4 & 12.1 \\
\hline $\mathrm{A}_{2}$ fraction of $\mathrm{ASCM}$ & $\begin{array}{l}\mathrm{A}_{2-}^{-} \\
\mathrm{ASCM}\end{array}$ & 1.188 & 9.4 & 0.127 & 6.2 & 12.2 \\
\hline $\begin{array}{l}\text { trapped compounds of } \\
\text { ASCM }\end{array}$ & $\begin{array}{l}\text { TC- } \\
\text { ASCM }\end{array}$ & 0.128 & 2.5 & 0.051 & 6.3 & 11.7 \\
\hline Merey vacuum residues & ARVM & 9.127 & 15.8 & 0.578 & 6.3 & 12.1 \\
\hline$A_{1}$ fraction of ARVM & $\begin{array}{l}\mathrm{A}_{1^{-}} \\
\text {ARVM }\end{array}$ & 5.711 & 20.1 & 0.284 & 6.1 & 12.1 \\
\hline $\mathrm{A}_{2}$ fraction of ARVM & $\begin{array}{l}\mathrm{A}_{2-}^{-} \\
\text {ARVM }\end{array}$ & 9.037 & 32.8 & 0.276 & 6.3 & 12.1 \\
\hline $\begin{array}{l}\text { trapped compounds of } \\
\text { ARVM }\end{array}$ & $\begin{array}{l}\text { TC- } \\
\text { ARVM }\end{array}$ & 1.334 & 27.5 & 0.049 & 6.3 & 12.7 \\
\hline
\end{tabular}

crude oils have a structure formed by a cluster of $A_{1}$ and $A_{2}$ molecules. The colloidal core would be formed by a stack of $A_{1}$ molecules, and the periphery would be occupied by soluble $A_{2}$ molecules and other crude oil components. The above trapping capacity of asphaltenes lets us suppose that other crude oil components would be trapped in the colloid periphery between $A_{1}$ and $A_{2}$ and would be very difficult to remove from asphaltenes when they are separated from the crude oil. ${ }^{11}$

In this work, we are interested in the study of the changes in the EPR line intensity, from free radicals and vanadium $\left(\mathrm{VO}^{+2}\right)$ of asphaltenes fractionated $\left(A_{1}\right.$ fraction, $A_{2}$ fraction and trapped compounds) obtained from Merey heavy crude oils and their vacuum residues, due to the temperature changes. The obtained temperatures provide very important information about aggregation processes in asphaltenes, the magnetic order-disorder transition at very low temperatures in free radicals and vanadium species, as well as a correlation between magnetic properties and intrinsic characteristics of the asphaltenes fractionated.

\section{MATERIALS AND METHODS}

Precipitation of Asphaltenes. Asphaltenes were precipitated from Merey heavy crude oil ( $16^{\circ} \mathrm{API}$, asphaltenes $\left.8.2 \%\right)$ and its vacuum residue $\left(3.3^{\circ} \mathrm{API}\right.$, asphaltenes $\left.18.2 \%\right)$. Merey heavy crude oil was obtained from the western coast of the Lake Maracaibo. Asphaltenes precipitation was conducted as described earlier. ${ }^{7,12}$

Fractionation by the p-Nitrophenol (PNP) Method. Using the PNP method, three fractions of the asphaltenes were obtained: $A_{1}$ fraction (low-soluble fraction of asphaltene), $A_{2}$ fraction (high-soluble fraction of asphaltene), and trapped compounds. Asphaltenes fractionation provides detailed information about the free radical environment and behavior. The most important property of these fractions is the large solubility difference. The $A_{2}$ fraction solubility usually equals that of the entire asphaltene sample $\left(50-100 \mathrm{~g} \mathrm{~L}^{-1}\right.$ in toluene at room temperature), whereas the solubility of $A_{1}$ is about $0.1 \mathrm{~g} \mathrm{~L}^{-1}$ under the same conditions. ${ }^{11}$ This solubility difference could be due to the way the polycyclic units (PCUs) are connected between them in $A_{1}$ and $A_{2}$.

The separation of asphaltenes in the $A_{1}$ fraction, $A_{2}$ fraction, and trapped compounds (TCs) by the $p$-nitrophenol method ${ }^{9,10}$ involve a saturated solution of $p$-nitrophenol (PNP) in cumene $(8 \mathrm{~g} / \mathrm{L})$ with stirring and soft heating. Once the PNP was dissolved, $8 \mathrm{~g}$ of asphaltenes were added with continuous agitation and then let settle for $72 \mathrm{~h}$ at room temperature. Subsequently, vacuum filtering was conducted to obtain $\mathrm{A}_{1}+\mathrm{PNP}$ (solid) and $\mathrm{A}_{2}+\mathrm{PNP}+\mathrm{TC}$ (filtered). The solid $A_{1}+$ PNP was dissolved in chloroform, and it was washed several times with aqueous $\mathrm{NaOH}$ solution $(5 \% \mathrm{~m} / \mathrm{v})$ to remove PNP (yellow coloration). The removal of $\mathrm{NaOH}$ was carried out with continuous washes of distilled water until neutral $\mathrm{pH}$ was obtained. The $A_{1}$ fraction was obtained after solvents were evaporated, followed by drying at $60{ }^{\circ} \mathrm{C}$.

The filtrate $\mathrm{A}_{2}+\mathrm{PNP}+\mathrm{TC}$ was evaporated, diluted in three volumes of $n$-heptane with constant stirring, and left to settle for $24 \mathrm{~h}$. It was filtered under a vacuum, and $\mathrm{A}_{2}+\mathrm{PNP}$ (solid) and TC + PNP (filtered) were obtained. The solid $\mathrm{A}_{2}+\mathrm{PNP}$ was dissolved in chloroform, and the removal of PNP was carried out as described above. Once the chloroform was evaporated, the $\mathrm{A}_{2}+$ impurities fraction was subjected to Soxhlet extraction with cyclohexane until clear washings were obtained. Subsequently, it was introduced in an oven at $80^{\circ} \mathrm{C}$, and fraction $\mathrm{A}_{2}$ was obtained. The filtrate $\mathrm{TC}+\mathrm{PNP}$ was evaporated, and then it was diluted in chloroform with consecutive washes with $\mathrm{NaOH}$ solution $(5 \% \mathrm{~m} / \mathrm{v})$. Afterward, chloroform was evaporated, and the trapped compounds were obtained, followed by drying at $60{ }^{\circ} \mathrm{C}$.

Nuclear Magnetic Resonance Spectroscopy. ${ }^{1} \mathrm{H}$ NMR and ${ }^{13} \mathrm{C}$ NMR spectra were acquired on a Bruker DRX 300 spectrometer equipped with a direct detection QNP probe (Quattro Nucleus Probe) and operating at $300.02 \mathrm{MHz}$ for protons and $75.5 \mathrm{MHz}$ for carbon. Measurements were conducted with $80 \mathrm{mg}$ of each sample dissolved in deuterated chloroform $\left(\mathrm{CDCl}_{3}\right)$ with $99.8 \% \mathrm{D}$. Chromium acetylacetonate $\left[\mathrm{Cr}(\mathrm{acac})_{3}\right]$ was added to ensure complete relaxation between pulses, and then the samples were introduced in borosilicate tubes for NMR

Electron Paramagnetic Resonance Spectroscopy. The EPR experiments were carried out in an air atmosphere using a Bruker EMX spectrometer operating at the X-band $(\nu=9.33 \mathrm{GHz})$ with a rectangular cavity equipped with an $\mathrm{N}_{2}$ BRUKER temperature controller. The normalized area values of free radicals were determined using the 2,2-diphenyl-1-picrylhydrazyl (DPPH) radical as an external standard, and the most intense signals in the multiplet of $\mathrm{V}^{+4}$ were determined employing 5,10,15,20-tetraphenyl-21H,23Hporphine vanadium(IV) oxide as a standard. All the measurements were performed with $0.50 \mathrm{mg}$ of each sample in the temperature range $90 \leq T \leq 670 \mathrm{~K}$, in stages of $15 \mathrm{~K}$; each of the measured EPR spectra represents a point in the graph of the reciprocal of the normalized area $\left(1 / A_{\mathrm{N}}\right)$ as a function of temperature. In Table 1 the $\Delta H_{\mathrm{PP}}$ and the spin/g concentrations for $\mathrm{FR}$ and $\mathrm{V}^{+4}$ in all the studied samples are shown.

The FR/ $\mathrm{V}^{+4}$ ratio is higher for the ARVM than for the ASCM ratio. This may be due to the presence of mobile petroporphyrins additional to the occluded petroporphyrins in the structure of asphaltenes generated by the action of the temperature on the samples in the vacuum towers. ${ }^{13,14}$ Interaction of different compounds with asphaltenes and their aggregates is an interesting phenomenon, which is relevant to properties such as swelling and solvent interaction. This effect has been studied by several authors and the nature of the interaction still in discussion..$^{15-18}$ The adsorption and 
(a)

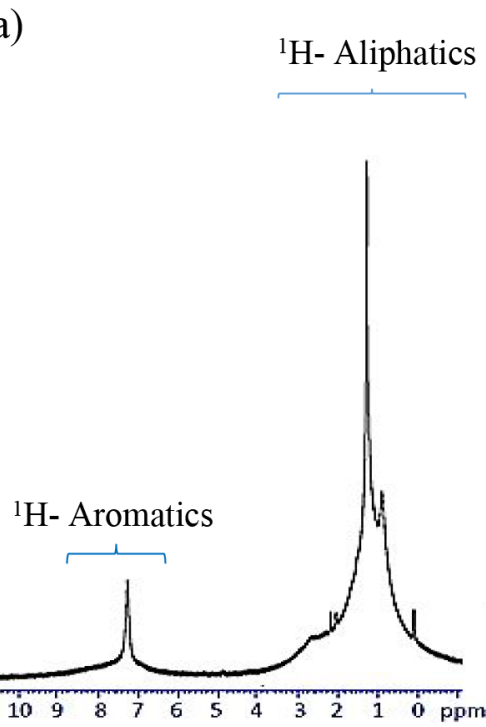

(b)

${ }^{1} \mathrm{H}$ - Aliphatics

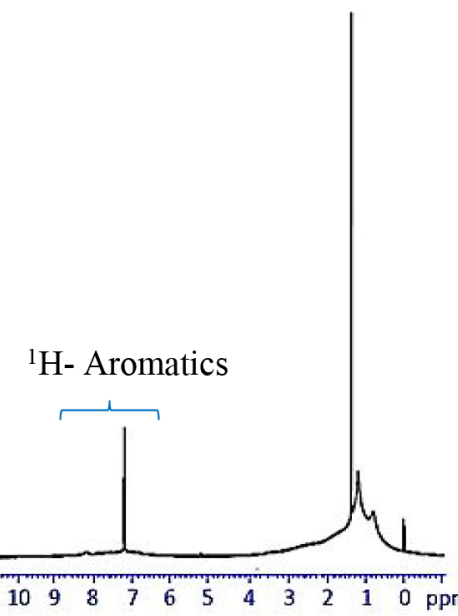

(c)

${ }^{1} \mathrm{H}$ - Aliphatics

Figure 1. ${ }^{1} \mathrm{H}$ NMR spectra of ASCM asphaltenes: (a) $A_{1}$ fraction, (b) $A_{2}$ fraction, (c) trapped compounds.

(a)

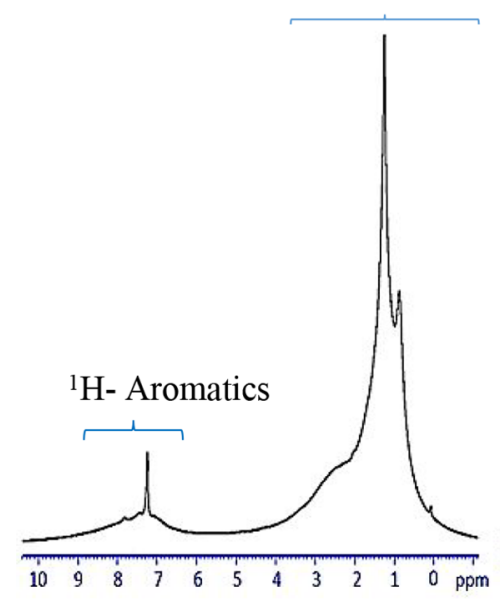

(b)

${ }^{1} \mathrm{H}$ - Aliphatics

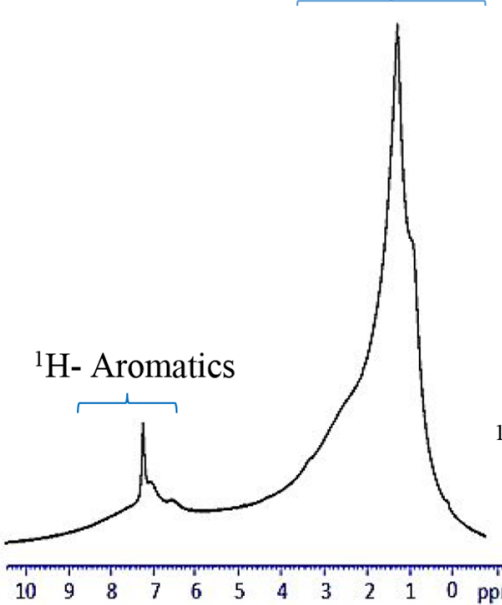

(c)

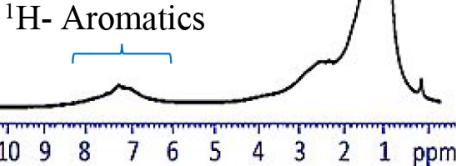

Figure 2. ${ }^{1} \mathrm{H}$ NMR spectra of ARVM asphaltenes: (a) $A_{1}$ fraction, (b) $A_{2}$ fraction, (c) trapped compounds.

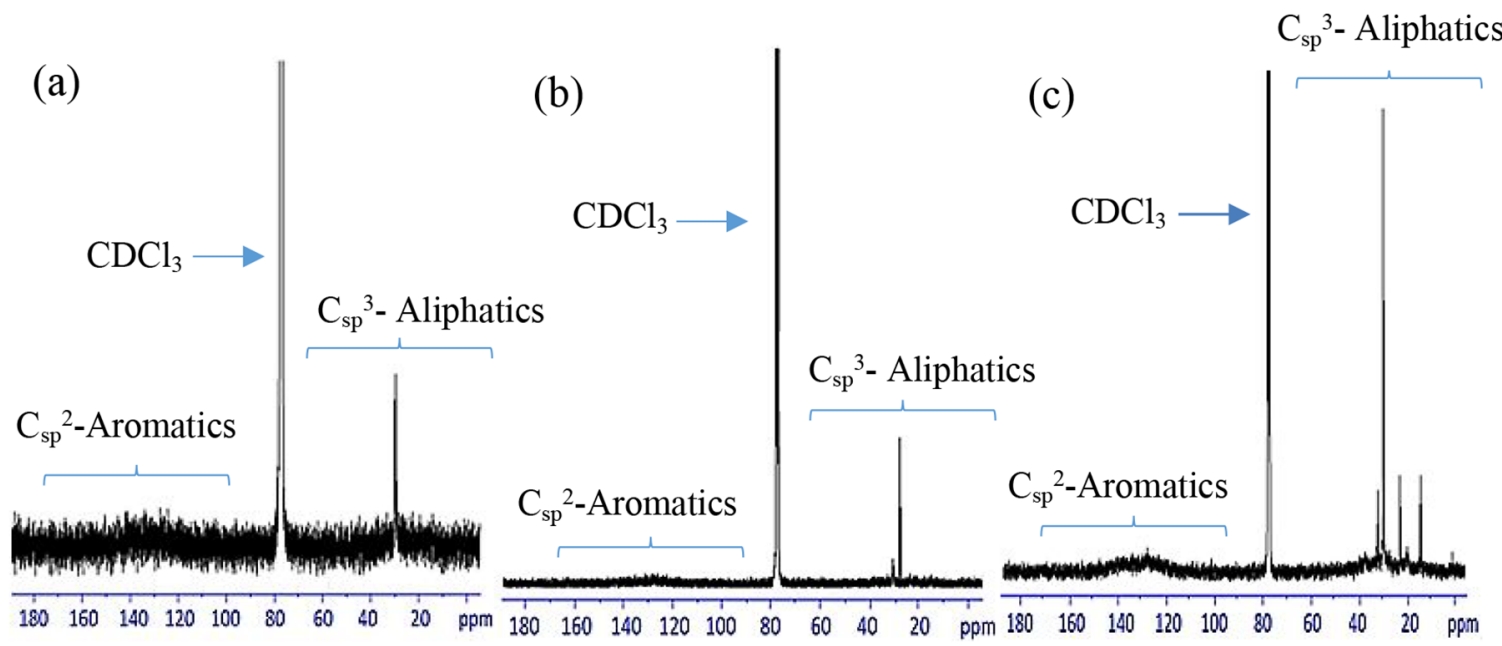

Figure 3. ${ }^{13} \mathrm{C}$ NMR spectra of ASCM asphaltenes: (a) $A_{1}$ fraction, (b) $A_{2}$ fraction, (c) trapped compounds. 
(a)

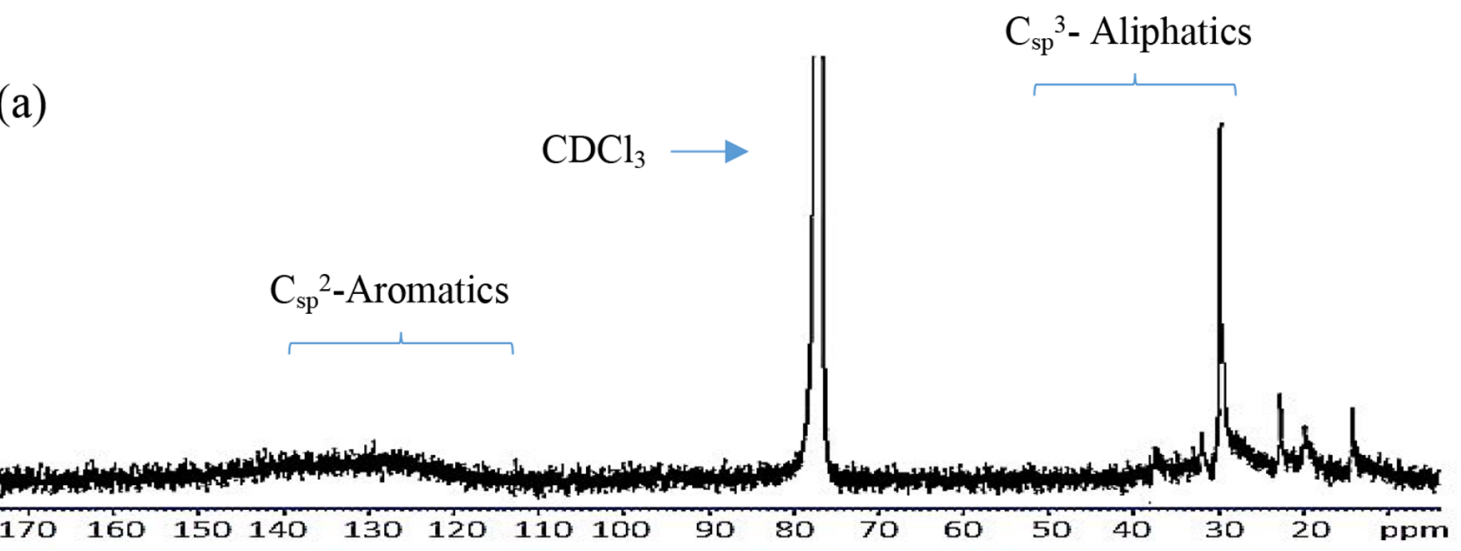

(b)

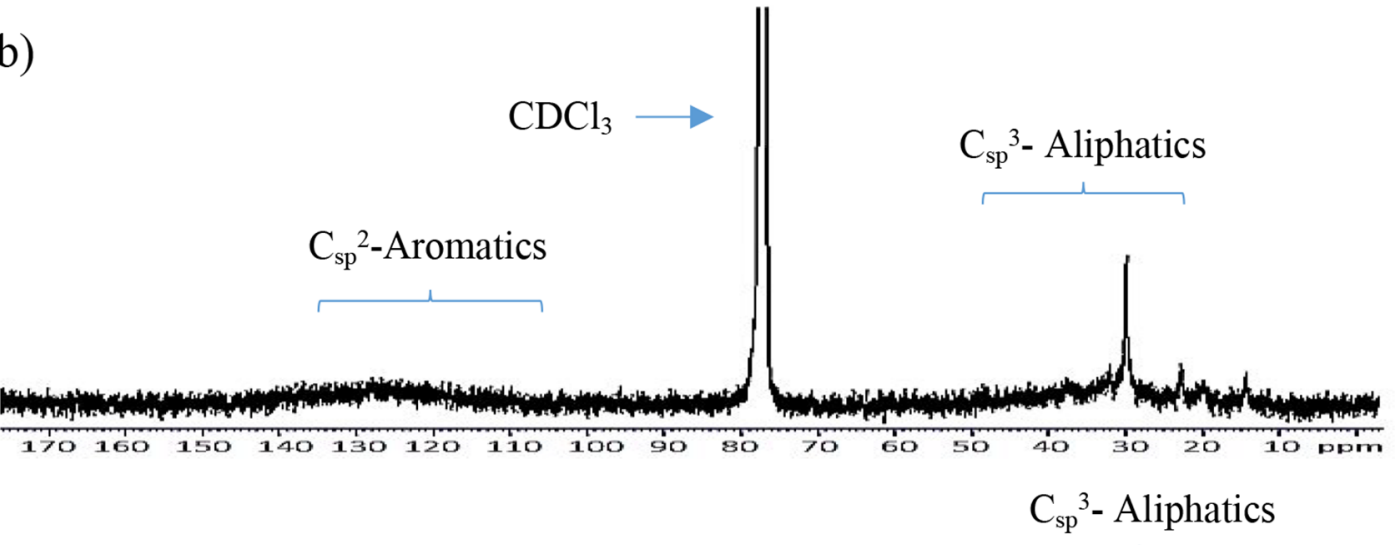

(c)

Figure 4. ${ }^{13} \mathrm{C}$ NMR spectra of ARVM asphaltenes: (a) $A_{1}$ fraction, (b) $A_{2}$ fraction, (c) trapped compounds.

occlusion of different compounds in asphaltenes aggregates have been studied by Castillo et al.; ${ }^{19}$ they proposed the existence of two mechanisms for trapping these molecules: occlusion and adsorption onto aggregates with the occlusion as the predominant effect. ${ }^{19}$

The $B$ parameter has been used as a sensitive indicator of the tetragonal distortion to clarify any change in the $\mathrm{V}=\mathrm{O}$ bond length and distance of four nitrogen ligands in the basal plane, as reported in the literature, ${ }^{20}$ which can be derived as follows:

$$
\begin{gathered}
B=\frac{\Delta g_{\|}}{\Delta g_{\perp}} \\
\Delta g_{\|}=g_{\|}-g_{\mathrm{e}} \\
\Delta g_{\perp}=g_{\perp}-g_{\mathrm{e}}
\end{gathered}
$$

where $g_{\|}$and $g_{\perp}$ are the parallel and perpendicular values of the $g$ parameter for the vanadyl complexes and $g_{\mathrm{e}}$ is the free electron $g$ value of $2.0023 .^{21}$

\section{RESULTS AND DISCUSSION}

Nuclear Magnetic Resonance Spectroscopy. ${ }^{1} \mathrm{H}$ NMR spectra of the $A_{1}$ fraction, $A_{2}$ fraction, and trapped compounds from ASCM and ARVM are shown in Figures 1 and 2, respectively. Regardless of their origin, similar behavior is observed: displacements between 0 and $2 \mathrm{ppm}$ related to proton couplings in groups $\mathrm{R}-\mathrm{CH}_{3}, \mathrm{R}-\mathrm{CH}_{2}-\mathrm{R}$, and $\mathrm{R}_{3}-\mathrm{CH}$; displacements between 2 and $3 \mathrm{ppm}$ in accordance with $\alpha$ protons to aromatic rings; displacements between 4 and $5 \mathrm{ppm}$ according to protons $=\mathrm{CH}$; and a well-defined signal around 8 ppm corresponding to aromatic protons. 
${ }^{13} \mathrm{C}$-NMR spectra obtained of $\mathrm{A}_{1}$ fractions, $\mathrm{A}_{2}$ fractions, and trapped compounds of ASCM and ARVM are shown in Figures 3 and 4, respectively. In all the spectra, signals in the zone corresponding to aliphatic carbons $(10-70 \mathrm{ppm})$ are observed below $30 \mathrm{ppm}$ associated with the presence of methyl and methylene carbons. At the same time, a wide aromatic region is observed for all cases, being more marked for the fractions coming from ARVM asphaltenes.

EPR Study of Free Radicals. In Figure 5, we show the EPR spectrum for ASCM asphaltenes at room temperature. A

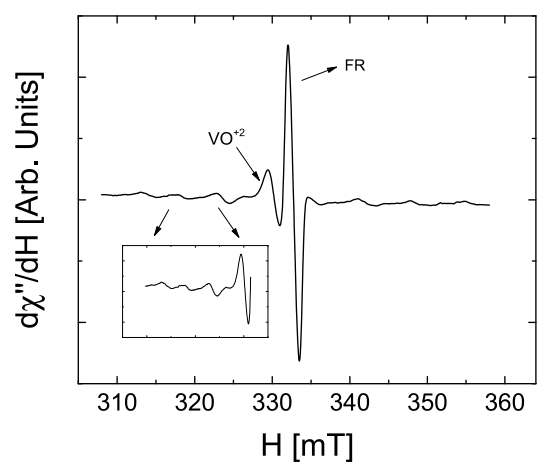

Figure 5. EPR spectrum of ASCM asphaltenes at room temperature.

typical spectrum for crude oils ${ }^{22-24}$ is shown, in which a very intense and symmetrical signal around $g=2.0052 \pm 0.0005$, attributed to the average of all contributions of the different stable carbon-centered "free radicals" (FR) in the sample, is observed, and a less intense set of signals corresponding to $\mathrm{V}^{+4}$ in accord with a nuclear spin $I=7 / 2$ for ${ }^{51} \mathrm{~V}$ (in the inset of Figure 5, an extension of this line octet is shown). ${ }^{7}$

Temperature dependence of the inverse of the normalized area of the EPR spectrum $\left(1 / A_{N}\right)$ for FRs in asphaltenes from Merey heavy crude oil and its fractions is shown in Figure 6. Linear behavior is observed for the $1 / A_{\mathrm{N}}$ vs $T$ curve for the FRs in $A_{1}$-ASCM asphaltenes (Figure 6a), in the temperature range $90 \leq T \leq 450 \mathrm{~K}$, in accord with the Curie-Weiss law for paramagnetic compounds:

$$
\frac{1}{\chi}=\frac{T}{C}+\frac{\theta}{C} \propto \frac{1}{A_{\mathrm{N}}}
$$

where $\chi$ is the magnetic susceptibility of the samples studied, $T$ is the absolute temperature, $C$ is the Curie constant, $\theta$ is the Curie-Weiss temperature, and $A_{\mathrm{N}}$ is the normalized area of the absorption curve in the EPR spectrum.

A change in the slope from positive to negative is observed at $450 \mathrm{~K}$; this change may be associated with an increase in the concentration of the FRs number generated by chain scissions in the samples due to temperature effects. The behavior of the FRs concentration has several and complex origins. It is known that the thermal treatment leads to the destruction of the asphaltene complexes onto four to five small pieces, ${ }^{25}$ and mechanisms such as generation, recombination, and singlettriplet transitions of state can occur. ${ }^{26,27}$ In another way, the majority of the organic free radicals are concentrated in the structure of a condensed polyaromatic core of asphaltene molecules; ${ }^{28}$ the changes in the structure, caused by thermal treatment, can peel the onion and strip the radicals, causing an increase in the concentration of the free radicals observed by EPR. ${ }^{1}$ We named this temperature the cusp temperature 1 $\left(T_{\mathrm{c} 1}\right)$. The other three abrupt changes in slope, named $T_{\mathrm{v} 1}, T_{\mathrm{c} 2}$, and $T$ cracking, can be observed in the graph. The meaning of $T_{\mathrm{v} 1}, T_{\mathrm{c} 2}$, and cracking temperatures were described earlier. ${ }^{7}$ The increase in the FR concentration occurs up to a temperature named valley temperature $1\left(T_{\mathrm{vl}}\right)$, where the recombination of FRs starts to lower its concentration. This phenomenon takes place until reaching a cusp temperature named $T_{\mathrm{c} 2}$, in which mass losses or structural changes may occur and then a cracking temperature appears. Critical temperatures $T_{\mathrm{c} 1}, T_{\mathrm{v} 1}$, ad $T_{\mathrm{c} 2}$ and cracking are observed in both fractions $A_{1}$. Above $T=600 \mathrm{~K}$, a decrease in the FR concentration was observed in almost all the samples studied, maybe as a result of the fast recombination of FRs to form new chemical bonds. This temperature can be associated with the cracking temperature of the asphaltenes. ${ }^{7,12}$ In most of the samples, a valley at high temperatures, except for trapped compounds, was observed. No cracking temperature was observed in the trapped compounds. Trapped compounds (TCs) have low molecular mass; they are released from whole asphaltenes in their fractions $A_{1}$ and $A_{2}$ after using the pnitrophenol (PNP) method. This is confirmed by Acevedo et al., ${ }^{11}$ using laser desorption ionization-time of flight mass spectrometry (LDI-TOF MS). They observed a bimodal nature of molecular mass distribution (MMD) of asphaltenes, because of the presence of TCs in the low molecular mass range, and it is not present in the MMD corresponding to $A_{1}$ and $\mathrm{A}_{2}$. This low molecular mass of the TCs may be responsible for the lack of detection of cracking temperature in these compounds. We can observe in Table 2 that fraction $\mathrm{A}_{1^{-}}$ ASCM shows a $T_{\mathrm{c} 1}$ temperature slightly higher than that for ASCM, and fraction $\mathrm{A}_{1}$-ARVM shows the same temperature $T_{\mathrm{c} 1}$ as ARVM. The fraction $\mathrm{A}_{2}$ shows a $T_{\mathrm{cl}}$ lower than its respective crude oils, while both trapped compounds show very low $T_{\mathrm{c} 1}$ temperatures concerning all the samples studied. This behavior tells us that the generation of FRs in the $A_{1}$ fractions begins after or at the same temperature as its respective crude oils, while for the $A_{2}$ fractions we need low thermal energy to generate FRs. In trapped compounds, FRs begin to appear at temperatures near room temperature. On the other hand, in Table 2 we can observe that temperature $T_{\mathrm{v} 1}$ for $A_{1}$-ASCM is lower than that for the ASCM, maybe because the unfractionated sample keeps all its native constituents and it is easy to obtain FRs in a greater temperature range, but $T_{\mathrm{v} 1}$ in $A_{1}$-ARVM is greater than that for ARVM, maybe in this case because a great quantity of these native constituents has been removed to obtain the vacuum residues, while in $\mathrm{A}_{2}$-ASCM fraction $T_{\mathrm{v} 1}$ the temperature is lower than the same for ASCM and $T_{\mathrm{v} 1}$, for $\mathrm{A}_{2}$-ARVM, which is the same as ASCM, is greater than that for ARVM for the same reason as in the case of $A_{1}$ fractions. In Table 2, we can observe that temperature $T_{\mathrm{c} 2}$ is the same for almost all of the samples $(=540 \mathrm{~K})$, except for the trapped compounds and for the ARVM in which this temperature is lowest. This temperature is associated with mass losses or structural changes, characteristics of crude oil and that do not depend on their fractions, the same behavior we obtain for the cracking temperature.

Curie-Weiss-like temperatures for all studied samples indicate that FRs tend to align in an antiferromagnetic order at low temperatures $(\theta<0)$. However, these temperatures tend to be lower for unfractionated samples ASCM and ARVM ( -60 and $-200 \mathrm{~K}$, respectively), maybe due to FR's interactions in the unfractionated samples being stronger that in the fractions and trapped compounds. 
(a)

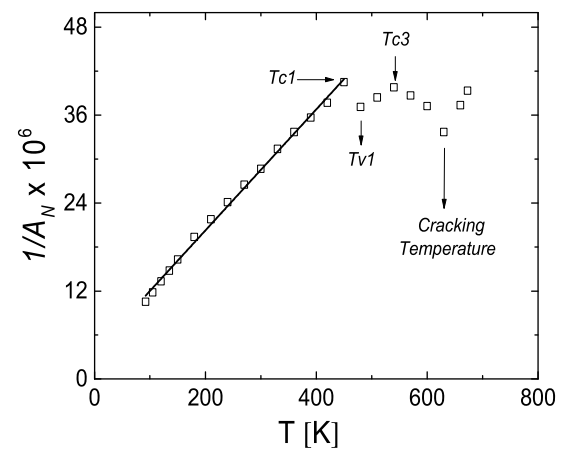

(c)

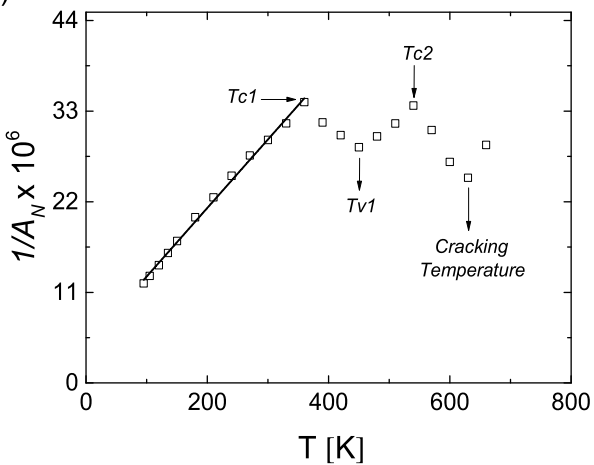

(e)

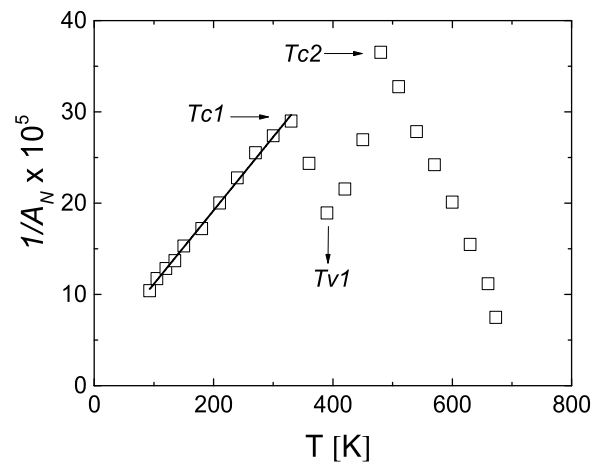

(b)

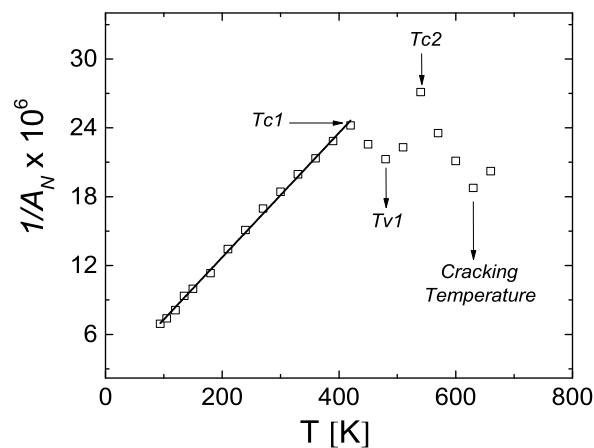

(d)

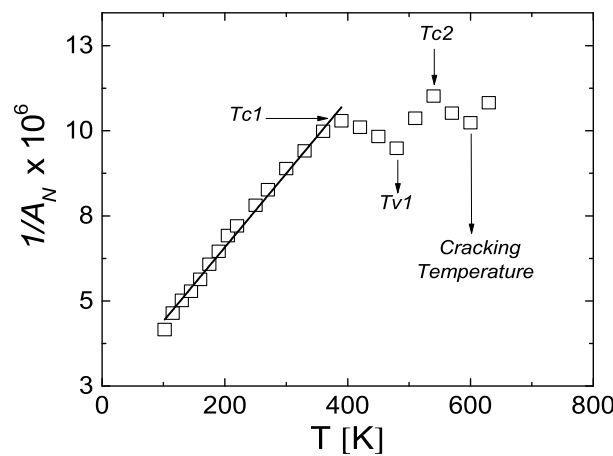

(f)

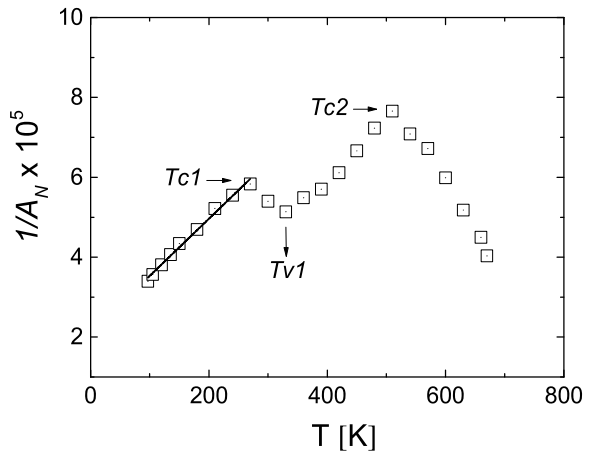

Figure 6. Reciprocal of the normalized area for free radicals vs temperature: (a) $A_{1}-A S C M$, (b) $A_{1}-A R V M, ~(c) ~ A_{2}-A S C M,(d) A_{2}-A R V M$, (e) TCASCM, (f) TC-ARVM.

Table 2. Temperatures Obtained by Fitting the Inverse of the Normalized Area for Free Radicals

\begin{tabular}{lccccc} 
asphaltenes & $\begin{array}{c}T_{\mathrm{c1}} \\
(\mathrm{K})\end{array}$ & $\begin{array}{c}T_{\mathrm{v1}} \\
(\mathrm{K})\end{array}$ & $\begin{array}{c}T_{\mathrm{c} 2} \\
(\mathrm{~K})\end{array}$ & $\begin{array}{c}\text { cracking temperatures } \\
(\mathrm{K})\end{array}$ & $\begin{array}{c}T_{\mathrm{CW} 1} \\
(\mathrm{~K})\end{array}$ \\
$\mathrm{A}_{1}$-ASCM & 450 & 480 & 540 & 630 & -45 \\
$\mathrm{~A}_{2}$-ASCM & 360 & 450 & 540 & 630 & -55 \\
TC-ASCM & 330 & 390 & 480 & & -38 \\
ASCM & 420 & 510 & 540 & 600 & -60 \\
A $_{1}$-ARVM & 420 & 480 & 540 & 630 & -35 \\
A $_{2}$-ARVM & 390 & 480 & 540 & 600 & -103 \\
TC-ARVM & 270 & 330 & 510 & & -147 \\
ARVM & 420 & 450 & 510 & 600 & -200 \\
\hline
\end{tabular}

EPR Study of $\mathrm{VO}^{2+}$ Signal. Vanadium species in asphaltenes are generally in porphyrin structures with an oxidation state of $+4(\mathrm{~V}=\mathrm{O})^{+2}$. The $\mathrm{V}^{+4}$ ions are detectable by EPR due to the $3 \mathrm{~d}^{1}$ electron configuration (electron spin $S=$
$1 / 2$, and nuclear spin $I=7 / 2) .^{29,30}$ The reciprocal of the normalized area as a function of temperature is shown in Figure $7 \mathrm{a}$ for the ASCM, its fractions, and trapped compounds. In Figure $7 \mathrm{~b}$, we show results for the ARVM, its fractions, and trapped compounds. The $1 / A_{\mathrm{N}}$ vs $T$ curve for all the samples, except the TC-ARVM sample, could be fitted using linear fittings in three regions or temperature ranges. In the temperature range $90 \leq T \leq T_{1}$, we observe at temperature $T_{1}$ a slight change in the slope and then a linear behavior in the temperature range $T_{1} \leq T \leq T_{2}$. After the temperature $T_{2}$, an abrupt change in the slope is observed, and linear behavior of the $1 / A_{\mathrm{N}}$ vs $T$ curve in the $T_{2} \leq T \leq 670 \mathrm{~K}$ occurs. In Figure $7 \mathrm{c}$,d, we show the behavior for the ASCM and ARVM samples (the rest of the samples are shown in the Supporting Information). It is important to notice that the $T_{1}$ temperature is in accord with $T_{\mathrm{cl}}$, and the $T_{2}$ temperature is in accord with the corresponding $T_{\mathrm{c} 2}$ temperature for FRs. The correspond- 


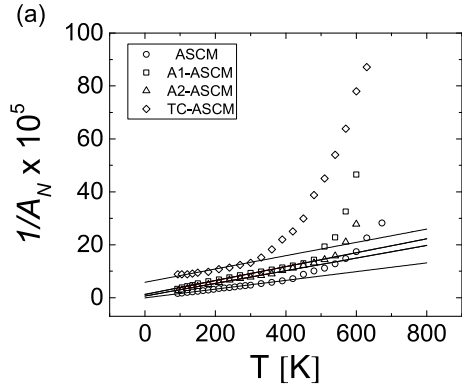

(c)

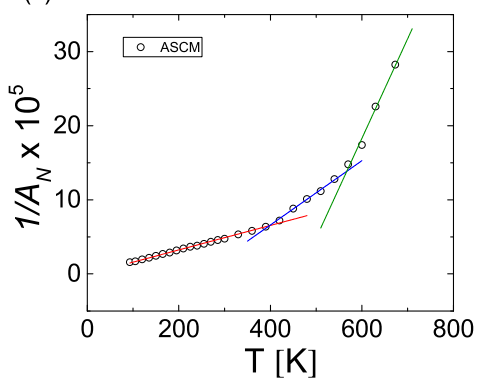

(b)

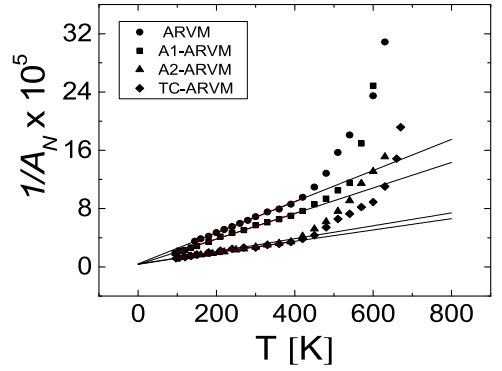

(d)

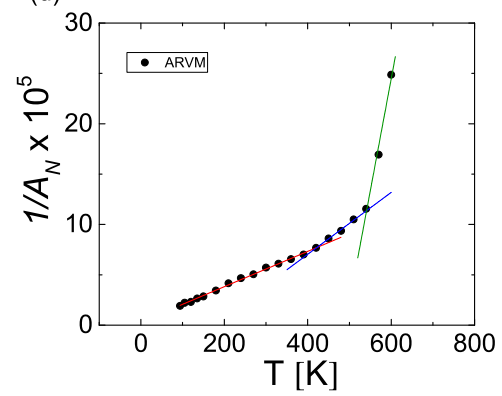

Figure 7. Reciprocal of the normalized area for the most intense signal in the multiplet of $\mathrm{V}^{+4}$ vs temperature. (a) ASCM, (b) ARVM, (c) ASCM, and (d) ARVM.

ence of these two temperatures $\left(T_{1}\right.$ and $\left.T_{2}\right)$ with the $\left(T_{\mathrm{c} 1}\right.$ and $T_{\mathrm{c} 2}$ ) temperatures in the FRs is an indication that the neighborhood of the vanadium ion is affected with the generation of FRs and suggests that at the $T_{\mathrm{c} 2}$ temperature, conformational changes in the studied samples are occurring. In the case of the TC-ARVM sample, more than two temperatures appear, and only the $T_{1}$ temperature shows agreement of the temperatures corresponding to its FRs. One of the reasons for this behavior is the fact that the spin concentration for the TC samples is very low, and a very noisy EPR spectrum is obtained. Table 3 shows the results obtained for all the samples studied.

Table 3. Temperatures Obtained for the Most Intense Signal in the $\mathrm{V}^{+4}$ Multiplet

\begin{tabular}{lccclccc} 
asphaltenes & $T_{1}$ & $T_{2}$ & $T_{\mathrm{CW1}}$ & & $T_{1}$ & $T_{2}$ & $T_{\mathrm{CW} 1}$ \\
$\mathrm{~A}_{1}$-ASCM & 450 & 540 & -47 & $\mathrm{~A}_{1}$-ARVM & 420 & 540 & -18 \\
$\mathrm{~A}_{2}$-ASCM & 360 & 540 & -26 & $\mathrm{~A}_{2}$-ARVM & 390 & 540 & -53 \\
TC-ASCM & 330 & 480 & -232 & TC-ARVM & 270 & 420 & -65 \\
ASCM & 420 & 540 & 4 & ARVM & 420 & 540 & -19 \\
\hline
\end{tabular}

Curie-Weiss-like temperatures obtained from the most intense signal in the vanadium multiplet are listed in Table 3. The $T_{\mathrm{CW} 1}$ temperatures indicate that most of the samples have a type of antiferromagnetic interaction at low temperatures, in which the magnetic moments align quasi-antiparallel $(\theta<0)$, except for ASCM. The vanadium in ASCM asphaltenes displays a ferromagnetic-like order, while the vanadium in the rest of the samples shows an antiferromagnetic-like order at low temperatures. These results are consistent with previous work for the vanadyl octaethylporphyrinate derivative. ${ }^{31}$

It can be noticed that in both cases, ASCM and ARVM have Curie-Weiss-like (modulus) temperatures lower than their respective fractions and trapped compounds; this behavior is due to the spin density for vanadium, shown in Table 1, being greater for the fractions than for the unfractionated samples.
Temperature dependence of the $B$ parameter for the ASCM, $A_{1}$-ASCM, A $A_{2}$-ASCM, ARVM, $A_{1}$-ARVM, and $A_{2}$-ARVM from the EPR spectra of vanadyl porphyrins is shown in Figure 8 (for the trapped compounds, this parameter could not be obtained). For the unfractionated samples, three regions separated by temperatures, which we defined as $T_{\mathrm{B} 2}$ and $T_{\mathrm{B} 3}$, can be identified in the graph. Both temperatures $T_{\mathrm{B} 2}(=300$ $\mathrm{K})$ and $T_{\mathrm{B} 3}(=420 \mathrm{~K})$ are the same for the ASCM and ARVM samples. As the temperature rises, the $\Delta g_{\|} / \Delta g_{\perp}$ values for the $\mathrm{V}=\mathrm{O}$ complexes decrease, which results in an obvious reduction of the $B$ values, although their EPR spectra were still anisotropic; this behavior was observed up to the temperature we named $T_{\mathrm{B} 3}$. The high temperature increases the molecular motion, and thus the constraint on $\mathrm{V}=\mathrm{O}$ complexes, by their surrounding matrices, loosens, which improves the rotational mobility of $\mathrm{V}=\mathrm{O} .{ }^{32}$ The behavior of the $B$ parameter, as a function of temperature, for these samples was fitted using the following expression:

$$
B=B_{0}+m T^{c}
$$

where $B_{0}, m$, and $c$ are fitting parameters. In the case of ASCM and ARVM, the $c$ parameter takes the values 0.28 and 0.39 , respectively, in the low-temperature zone (near $1 / 3$ in both cases); and in the temperature range $T_{\mathrm{B} 2} \leq T \leq T_{\mathrm{B} 3}$, the parameter $c$ takes the values 0.90 and 1.00 , respectively, near a linear behavior in both cases. Cui et al. ${ }^{32}$ found three domains in atmospheric residue, which are classified according to the temperature range in an anisotropic domain (low temperatures), a transitional domain (intermediate temperatures), and an isotropic domain (high temperatures). In the temperature range named by $\mathrm{Cui}$ et al. as the anisotropic domain, a linear dependence of the $B$ parameter as a function of the temperature observed that this temperature range is in accord with the behavior observed in our results in the temperature range $T_{\mathrm{B} 2} \leq T \leq T_{\mathrm{B} 3}$, which is in correspondence with the anisotropic domain of Cui et al. Although the $c$ parameter takes the value $1 / 3$ below this linear temperature range, the system remains in the anisotropic domain. Maybe 

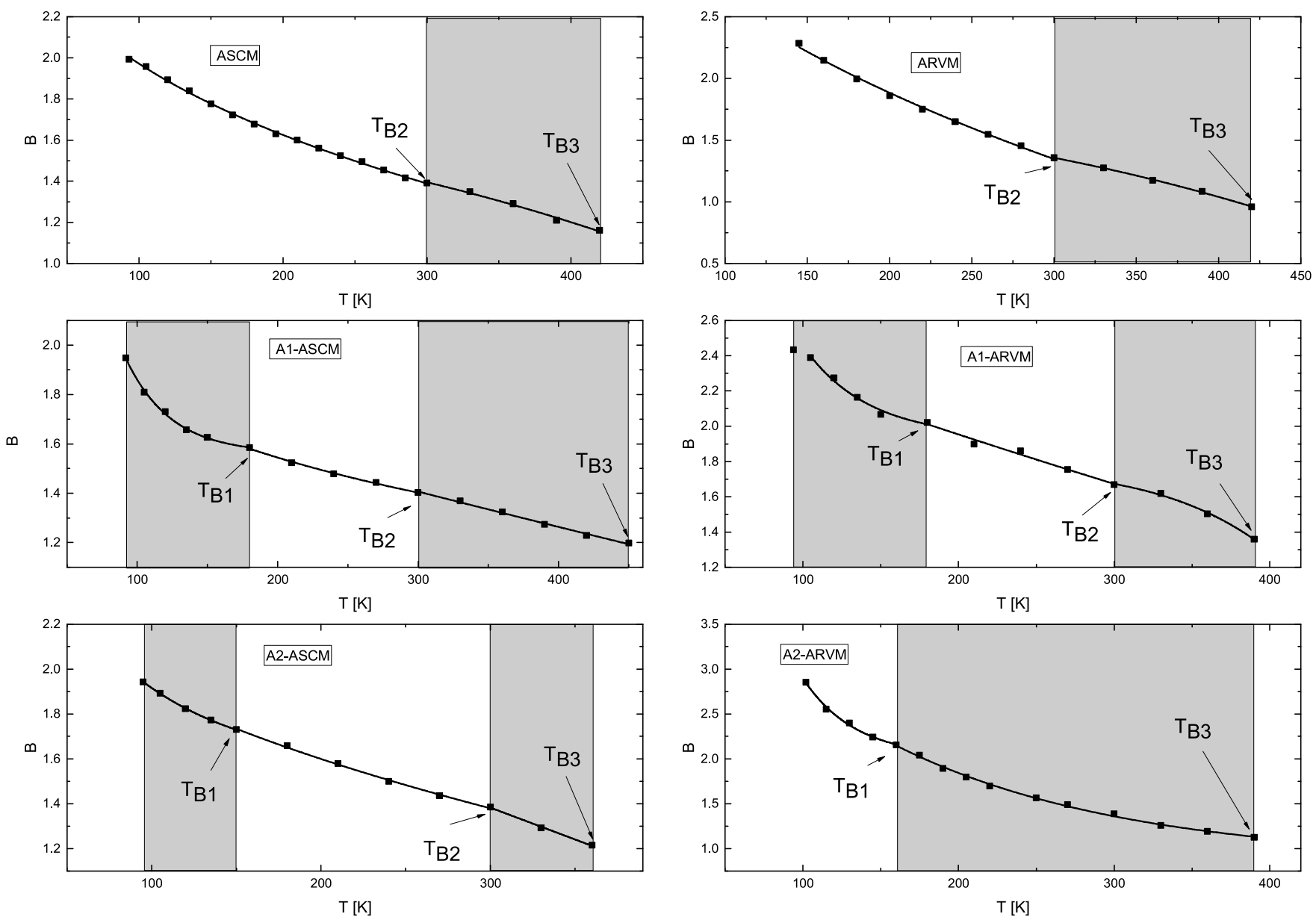

Figure 8. Temperature dependence of $B$ parameter for $V^{+4}$ in the EPR spectra for ASCM, $A_{1}-A S C M, A_{2}-A S C M, A R V M, A_{1}-A R V M$, and $A_{2}-A R V M$ samples.

the constraints acting on the $\mathrm{V}=\mathrm{O}$ bond increase very much with the decrease in temperature, this being responsible for the change in the value of the $c$ parameter. Temperatures above $T_{\mathrm{B} 3}$ may correspond to the transitional domain. According to Cui et al., there exists a critical temperature around $T=520 \mathrm{~K}$ for samples without any solvent, in which the spectrum becomes completely isotropic; this last region is in accord with the region $T \geq T_{\mathrm{B} 3}$ obtained from our EPR results.

For the fractions (except $A_{2}-A R V M$ ), four zones separated by $T_{\mathrm{B} 1}, T_{\mathrm{B} 2}$, and $T_{\mathrm{B} 3}$ temperatures are observed. In all the cases, except for $A_{2}-A R V M$, the $T_{B 2}$ temperature is the same (= $300 \mathrm{~K}$ ), and temperature $T_{\mathrm{B} 3}$ is lowest in the fractions than that for the unfractionated samples (except for the $A_{1}$-ASCM sample, in this case, $T_{\mathrm{B} 3}$ was the highest). In the fractions, a new region with an exponential decay in the temperature dependence behavior of the $B$ parameter at low temperatures is observed; in the case of the $A_{2}$-ARVM, this behavior remains up to the $T_{\mathrm{B} 3}$ temperature.

$$
B=B_{0}+A \mathrm{e}^{-T / t}
$$

where $B_{0}, A$, and $t$ are fitting parameters.

Above $T_{B 1}$, all the samples (except $A_{2}$-ARVM) were fitted using eq 5 .

There is an interaction of $\mathrm{V}=\mathrm{O}$ complexes with their surrounding organic molecules through noncovalent and physical bonding, such as strong van der Waals force, $\pi-\pi$ stacking, and hydrogen bonding. This interaction can be weakened with increasing temperature until the escape of $\mathrm{V}=$ O complexes from the constraint by their surrounding large molecules to exhibit a high rotational rate of the $V$ ion. ${ }^{32}$ It is worthwhile to mention that Cui et al. ${ }^{21,32}$ only observed a lineal behavior in their samples, probably because they used a very short-range of temperatures (only $20^{\circ} \mathrm{C}, 50{ }^{\circ} \mathrm{C}, 150{ }^{\circ} \mathrm{C}$, and $170{ }^{\circ} \mathrm{C}$ ).

The ratio between $\Delta g_{\|}$and $\Delta g_{\perp}$ is

$$
B=\frac{\Delta g_{\|}}{\Delta g_{\perp}}=\frac{4 \alpha^{2} \Delta E_{x z}}{\gamma^{2} \Delta E_{x^{2}-y^{2}}}
$$

where $\Delta g_{\|}=g_{\|}-g_{\mathrm{e}}$ is the relative shift of the parallel $g$ with respect to free-electron $g$ value $\left(g_{\mathrm{e}}=2.0023\right), \Delta g_{\perp}=g_{\perp}-g_{\mathrm{e}}$ is the relative shift of the perpendicular $g$ with respect to freeelectron $g$ value, $\Delta E_{x z}$ is the gap in energy from $\psi(\mathrm{b} 2)$ to $\psi(\mathrm{e})$ states, and $\Delta E_{x^{2}-y^{2}}$ is the excitation energy from $\psi$ (b2) to $\psi(\mathrm{b} 1)$ from the energy states of the samples.

The rotation of the $V$ ion becomes faster with the increase of temperature. According to our results, fractioning of the samples introduces new behavior in the $\mathrm{V}=\mathrm{O}$ bond which can be evidenced in the trends of the $B$ vs $T$ curve in all the temperature ranges, especially in the low-temperature zone in which a nonlinear behavior of the curve is obtained.

In order to evaluate the effect of the temperature in the mobility of the paramagnetic ions, we measure the distance of the $m_{\mathrm{I}}=1 / 2$ to $m_{\mathrm{I}}=3 / 2\left(\Delta B_{1 / 2,3 / 2}\right.$ parameter $)$ transition in the EPR spectra of the vanadium as the scaling of mobility. 
(a)

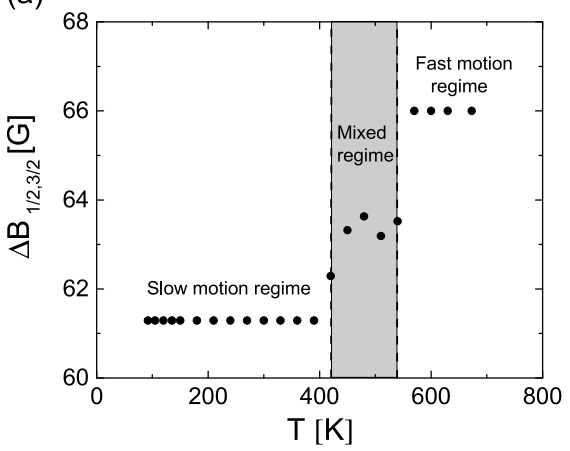

(c)

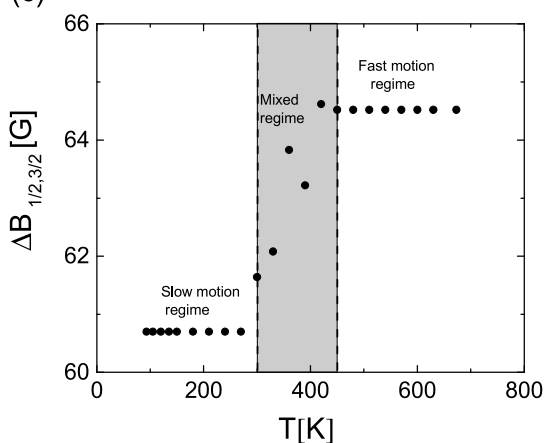

(b)

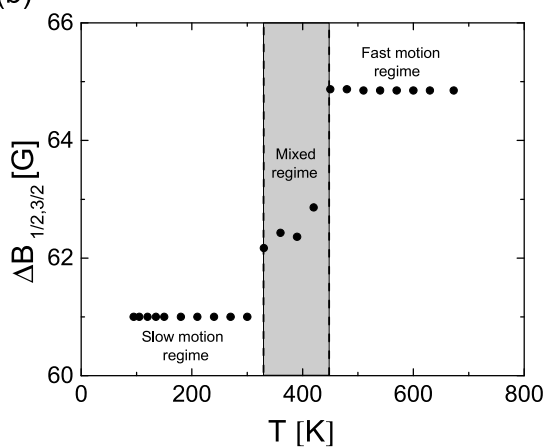

(d)

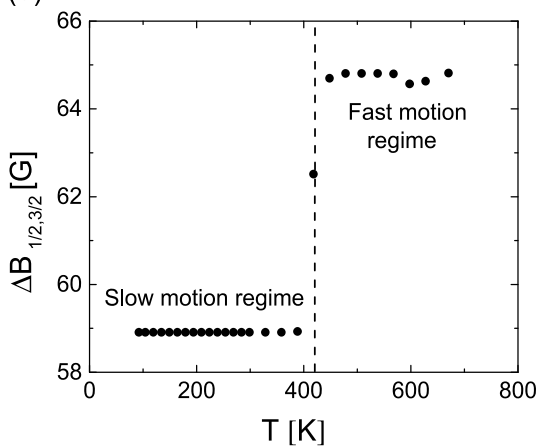

Figure 9. Temperature dependence of the experimental values of $\Delta B_{1 / 2,3 / 2}$ obtained for the $m_{\mathrm{I}}=1 / 2$ to $m_{\mathrm{I}}=3 / 2$ transition in the EPR spectra of vanadium: (a) $\mathrm{A}_{1}$-ASCM, (b) A - ASCM, (c) TC-ASCM, (d) ASCM.

The local magnetic fields induced by this type of motion initiate transitions with particular frequencies that influence the lineshape of EPR spectra. ${ }^{28}$ Also, the analysis of the temperature dependencies of $\Delta B_{1 / 2,3 / 2}$ and EPR spectra suggests a discontinuous change of the rotational correlation time in the region close to the phase transition. ${ }^{7,28}$

In Figure 9, we show the dependence on the temperature of the experimental values of $\Delta B_{1 / 2,3 / 2}$ obtained from the EPR spectra of vanadium for the $A_{1}$ fraction (Figure 9a), $A_{2}$ fraction (Figure 9b), trapped compounds (Figure 9c), and ASCM (Figure 9d). An abrupt jump in the temperature $T_{\mathrm{cl}}$ of the $\Delta B_{1 / 2,3 / 2}$ parameter, for the ASCM sample (Figure $9 \mathrm{~d}$ ), is observed. The coexistence of the slow-motion and fast-motion regimes (mixed regime) has been observed only in the fractions and in the trapped compounds. In all the cases, the transition temperature from the slow-to-mixed motion regime was near or equal to $T_{\mathrm{cl}}$ temperature. Likewise, temperature $T_{\mathrm{cl}}$ is the same temperature as that obtained from the $1 / A_{\mathrm{N}}$ when the curve moves away from linearity, so we can associate that behavior with a change in the motion regime of the samples. An interesting feature is that $T_{\mathrm{c} 1}$ is lower for the $\mathrm{A}_{2}$ fractions than the respective temperature for the $A_{1}$ fraction, indicating in the last case we need more energy to go from the slow-motion regime to the mixed regime. Pekerar et al., ${ }^{33}$ using spin-lattice relaxation times exhibited in asphaltenes of some heavy crude oils containing resins, indicate that these carbons relax more slowly than the equivalent carbons in the resin-free samples. This fact suggests higher mobility of the molecules in the sample in the presence of resins, and Gutiérrez et al., studying the fractionation of asphaltene by complex formation with p-nitrophenol, obtained two fractions $A_{1}$ and $A_{2}$ in which the precipitated asphaltene sample $A_{1}$ has very low solubility in toluene. The authors state that asphaltenes are a mixture of compounds with vast differences in solubility and suggest that their solutions in aromatic solvents are constituted by a colloidal phase, formed by the low-soluble fraction $A_{1}$ dispersed by a soluble asphaltene fraction $A_{2}$. The results obtained by Pekerar et al. ${ }^{33}$ suggest that, when neighbor molecular sectors are joined by alicyclic chains (aliphatic rings), an important impact on molecular mobility should be expected, and the results of Gutierrez et al. ${ }^{9}$ confirm that the mobility of fraction $A_{2}$ is greater than fraction $A_{1}$. These results are in perfect agreement with our results, which suggest the greatest mobility for fraction $\mathrm{A}_{2}$. The fractions and trapped compounds go from the mixed-to-fast motion regime in temperatures lower than those corresponding to $T_{2}$, indicating that the samples begin the free mobility of the $\mathrm{V}$ ion earlier than when the complete structural change is observed. All the samples, from vacuum residues, showed similar behavior, as we can see in the Supporting Information.

\section{SUMMARY}

From the fractionation of the ASCM and ARVM samples, we obtain the fractions $A_{1}, A_{2}$, and trapped compounds of each one. The structural and magnetic properties of each of the fractions and trapped compounds are very different from their unfractionated counterparts. The spin density in the fractions $\left(A_{1}, A_{2}\right)$-ASCM is slightly lower than that of the unfractionated sample, and in the trapped compounds the spin density was 1 order of magnitude lower than that of the unfractionated sample. In the case of the $\left(A_{1}, A_{2}\right)$-ARVM, they are sharply higher than the unfractionated sample. However, the ratio FRs $/ \mathrm{V}^{4+}$ of the spin density remains approximately the same for the ASCM and its fractions. In the case of ARVM and its fractions, a marked decrease in this ratio is observed in accordance with the highest values in the spin density of the 
$\mathrm{V}^{4+}$. In general, this ratio was highest for the ARVM, and its fractions with respect to that obtained for the ASCM and its fractions is indicative that the increase is in accord with an increment in the density of the samples when they are subjected to the vacuum tower. In both cases for ASCM and its fractions and ARVM and its fractions an increase in the spin density of the vanadium in the fractions with respect to the unfractionated samples is observed; this feature is evidence of an increase in asphaltenes concentration; however the relationship between this increase and the increment in the FRs remains constant for the ASCM but not for the ARVM in which the ratio $\mathrm{FR} / \mathrm{V}^{4+}$ was approximately half for the fractions compared to for the unfractionated and approximately double with respect to the ASCM fractions, the latter due to the thermal treatment in the vacuum tower. From the analysis of the EPR spectra of the FRs and, for the most intense peak corresponding to vanadium spectrum, we obtain the inverse of the normalized area; the temperatures $T_{\mathrm{c} 1}, T_{\mathrm{v} 1}$, and $T_{\mathrm{c} 2}$ which correspond to temperature in which the sample begins to generate FRs due to the temperature effect, the temperature in which FRs recombine, and the temperature in which some structural changes occur, respectively, were obtained. From the inverse of normalized area for the vanadium, we obtain $T_{1}$ and $T_{2}$ temperatures which are the same as $T_{\mathrm{c} 1}$ and $T_{\mathrm{c} 2}$ temperatures obtained for the FR signal. From the study of the temperature-dependence of the $B$ parameter, we observe that the fractionation of the samples introduces a new behavior at the lowest temperatures in all of them (ASCM and ARVM fractions) in the form of exponential decay; this behavior may be governed by an increase in the dipolar interactions of the spins. In addition, we obtain the linear behavior for the anisotropic zone founded by Cui et al. and a power law for the lowest temperatures in the unfractionated samples due to the freeze of the spins. The analysis of the B parameter has allowed us to identify its behavior in a wider range of temperatures, being able to establish functional relationships ranging from low temperatures to temperatures close to the isotropic domain. An analysis of the mobility of the vanadium ion gives a slow-to-mixed motion regimen temperature equal to $T_{\mathrm{c} 1}$ or $T_{1}$ and a mixed-to-fast motion regime near $T_{\mathrm{c} 2}$, indicating good accord between our results. For the fractions, our EPR results, by determination of temperature $T_{\mathrm{cl}}$, allowed us to corroborate that the fraction $\mathrm{A}_{2}$ has the greatest mobility following the results of Pekerar et al. and Gutiérrez et al.

\section{ASSOCIATED CONTENT}

\section{SI Supporting Information}

The Supporting Information is available free of charge at https://pubs.acs.org/doi/10.1021/acs.energyfuels.0c00254.

Figures A.1-A.6 (PDF)

\section{AUTHOR INFORMATION}

\section{Corresponding Author}

Pedro J. Silva - Laboratorio de Fisica de la Materia Condensada, Instituto Venezolano de Investigaciones Cientificas, Caracas 1020-A, Venezuela; Departamento de Fisica - FCNM, Escuela Superior Politécnica del Litoral, Ecuador; (이이.org/ 0000-0002-6409-8735; Email: pejosi@gmail.com
Author

Maury S. Hernández - Laboratorio de Física de la Materia Condensada, Instituto Venezolano de Investigaciones Cientificas, Caracas 1020-A, Venezuela

Complete contact information is available at:

https://pubs.acs.org/10.1021/acs.energyfuels.0c00254

\section{Notes}

The authors declare no competing financial interest.

\section{ACKNOWLEDGMENTS}

The authors wish to thank the Venezuelan Petroleum Technological Institute (INTEVEP), through the IVICINTEVEP agreement for the facilitation of all the samples in this study. On the other hand, this work is especially dedicated to the memory of Olga Castellano, who in life was a fundamental member of this teamwork and promoter of this research work.

\section{REFERENCES}

(1) Acevedo, S.; Escobar, G.; Ranaudo, M.; Piñate, J.; Amorín, A.; Díaz, M.; Silva, P. Observations about the structure and dispersion of petroleum asphaltenes aggregates obtained from dialysis fractionation and characterization. Energy Fuels 1997, 11 (4), 774-778.

(2) Mujica, V.; Nieto, P.; Puerta, L.; Acevedo, S. Caging of molecules by asphaltenes. A model for free radical preservation in crude oils. Energy Fuels 2000, 14 (3), 632-639.

(3) Acevedo, S.; Castro, A.; Negrin, J. G.; Fernandez, A.; Escobar, G.; Piscitelli, V.; Delolme, F.; Dessalces, G. Relations between asphaltene structures and their physical and chemical properties: the rosary-type structure. Energy Fuels 2007, 21 (4), 2165-2175.

(4) Kubo, T. Synthesis, physical properties, and reactivity of stable, $\pi$-conjugated, carbon-centered radicals. Molecules 2019, 24 (4), 665678.

(5) Yen, T.; Erdman, J.; Saraceno, A. Investigation of the nature of free radicals in petroleum asphaltenes and related substances by electron spin resonance. Anal. Chem. 1962, 34 (34), 694-700.

(6) Dickson, F. E.; Kunesh, C. J.; McGinnis, E. L.; Petrakis, L. Use of electron spin resonance to characterize the vanadium(IV)-sulfur species in petroleum. Anal. Chem. 1972, 44 (6), 978-981.

(7) Hernández, M.; Coll, D.; Silva, P. Temperature dependence of the electron paramagnetic resonance spectrum of asphaltenes from Venezuelan crude oils and their vacuum residues. Energy Fuels 2019, 33 (2), 990-997.

(8) Mommer, B. La valorización del Crudo Extrapesado de la Faja Petrolifera del Orinoco. Revista Venezolana de Economía y Ciencias Sociales 2004, 10 (2), 33-50.

(9) Gutierrez, L.; Ranaudo, M.; Mendez, B.; Acevedo, S. Fractionation of asphaltene by complex formation with p-nitrophenol. A method for structural studies and stability of asphaltene colloids. Energy Fuels 2001, 15 (3), 624-628.

(10) Acevedo, S.; Escobar, O.; Echevarria, L.; Gutiérrez, L.; Méndez, B. Structural analysis of soluble and insoluble fractions of asphaltenes isolated using the PNP method. Relation between asphaltene structure and solubility. Energy Fuels 2004, 18 (2), 305-311.

(11) Acevedo, S.; Cordero, J.; Carrier, H.; Bouyssiere, B.; Lobinski, $\mathrm{R}$. Trapping of paraffin and other compounds by asphaltenes detected by laser desorption ionization-time of flight mass spectrometry (LDI-TOF MS): role of $\mathrm{A} 1$ and $\mathrm{A} 2$ asphaltene fractions in this trapping. Energy Fuels 2009, 23 (2), 842-848.

(12) Hernández, M.; Castellano, O.; Silva, P. Effect of temperature on the EPR spectrum of asphaltenes. Acta Cientifica Venezolana 2015, 66 (3), 157-162.

(13) Brustolon, M.; Giamello, E. Electron Paramagnetic Resonance: A Practitioner's Toolkit; John Wiley \& Sons Inc.: EUA, 2009.

(14) Chilingarian, G.; Yen, T. Asphaltenes and asphalts 2. Developments in Petroleum Science, 40 B; Elsevier: Netherlands, 2000. 
(15) Liao, Z.; Zhou, H.; Graciaa, A.; Chrostowska, A.; Creux, P.; Geng, A. Adsorption/occlusion characteristics of asphaltenes: Some implication for asphaltenes structural features. Energy Fuels 2005, 19 (1), 180-186.

(16) Liao, Z.; Geng, A.; Graciaa, A.; Creux, P.; Chrostowska, A.; Zhang, Y. Different adsorption/occlusion properties of asphaltenes associated with their secondary evolution processes in oil reservoirs. Energy Fuels 2006, 20 (3), 1131-1136.

(17) Derakhshesh, M.; Bergmann, A.; Gray, M. Occlusion of polyaromatic compounds in asphaltene precipitates suggests porous nanoaggregates. Energy Fuels 2013, 27 (4), 1748-1751.

(18) Zhao, J.; Liao, Z.; Chrostowska, A.; Liu, Q.; Zhang, L.; Graciaa, A.; Creux, P. Experimental studies on the adsorption/occlusion phenomena inside the macromolecular structures of asphaltenes. Energy Fuels 2012, 26 (3), 1746-1755.

(19) Castillo, J.; Vargas, V. Metal porphyrin occlusion: Adsorption during asphaltene aggregation. Pet. Sci. Technol. 2016, 34 (10), 873879.

(20) Espinosa, M.; Campero, A.; Salcedo, R. Electron spin resonance and electronic structure of vanadyl-porphyrin in heavy crude oils. Inorg. Chem. 2001, 40 (18), 4543-4549.

(21) Cui, Q.; Nakabayashi, K.; Ma, X.; Ideta, K.; Miyawaki, J.; Marafi, A.; Al-Mutairi, A.; Park, J.; Yoon, S.; Mochida, I. Examining the molecular entanglement between $\mathrm{V}(\mathrm{O}$ complexes and their matrices in atmospheric residues by ESR. RSC Adv. 2017, 7, 3790837914.

(22) Wong, G.; Yen, T. An electron spin resonance probe method for the understanding of petroleum asphaltene macrostructure. J. Pet. Sci. Eng. 2000, 28 (1), 55-64.

(23) Piccinato, M.; Guedes, C.; Di Mauro, E. Crude oil emulsionscomposition stability and characterization. Crude Oil by EPR; Manar El-Sayed Abdel-Raouf, M., Ed.; IntechOpen, 2012; Chapter 8, pp 147-168, DOI: $10.5772 / 35602$

(24) Benamsili, L.; Korb, J.-P.; Hamon, G.; Louis-Joseph, A.; Bouyssiere, B.; Zhou, H.; Bryant, R. G. Multi-dimensional nuclear magnetic resonance characterizations of dynamics and saturations of brine/crude oil/mud filtrate mixtures confined in rocks: The role of asphaltene. Energy Fuels 2014, 28 (3), 1629-1640.

(25) Gafurov, M.; Volodin, M.; Rodionov, A.; Sorokina, A.; Dolomatov, M.; Petrov, A.; Vakhin, A.; Mamin, G.; Orlinskii, S. EPR study of spectra transformations of the intrinsic vanadylporphyrin complexes in heavy crude oils with temperature to probe the asphaltenes aggregation. J. Pet. Sci. Eng. 2018, 166, 363-368.

(26) Dolomatov, M; Gafurov, M; Rodionov, A; Mamin, G; Gonzalez, L. M.; Vakhin, A; Petrov, A; Bakhtizin, R; Khairudinov, I; Orlinskii, S Low-temperature thermal decomposition of heavy petroleum distillates: interconnection between the electrical properties and concentration of paramagnetic centers. IOP Conf. Series: Earth and Environmental Science 2018, 155, 012007.

(27) Dolomatov, M.; Rodionov, A.; Gafurov, M.; Petrov, A.; Biktagirov, T.; Bakhtizin, R.; Makarchikov, S.; Khairudinov, I.; Orlinskii, S. Concentration of paramagnetic centers at low-temperature thermal destruction of asphaltenes of heavy petroleum distillates. Magn. Reson. Solids. Electronic J. 2016, 18 (1), 1-7.

(28) Biktagirov, T.; Gafurov, M.; Volodin, M.; Mamin, M.; Rodionov, A.; Izotov, V.; Vakhin, A.; Isakov, D.; Orlinskii, S. EPR study of rotational mobility of vanadyl-porphyrin complexes in crude oil asphaltenes: probing the effect of thermal treatment of heavy oils. Energy Fuels 2014, 28 (10), 6683-6687.

(29) Mamin, G.; Gafurov, M.; Yusupov, R.; Gracheva, I.; Ganeeva, Y.; Yusupova, T.; Orlinskii, S. Toward the asphaltene structure by electron paramagnetic resonance relaxation studies at high fields (3.4 T). Energy Fuels 2016, 30 (9), 6942-6946.

(30) Trukhan, S.; Yudanov, V.; Gabrienko, A.; Subramani, V.; Kazarian, S.; Martyanov, O. In Situ Electron Spin Resonance study of molecular dynamics of asphaltenes at elevated temperature and pressure. Energy Fuels 2014, 28 (10), 6315-6321.

(31) Schulz, C. E.; Song, H.; Lee, Y. J.; Mondal, J. U.; Mohanrao, K.; Reed, C. A.; Walker, F. A.; Scheidt, W. R. Metalloporphyrin (-cation radicals. Molecular structure and spin coupling in a vanadyl octaethylporphyrinate derivate. An unexpected spin coupling path. $J$. Am. Chem. Soc. 1994, 116 (16), 7196-7203.

(32) Cui, Q.; Ma, X.; Nakabayashi, K.; Miyawaki, J.; Al-Mutairi, A.; Marafi, A. M. J.; Al-Otaibi, A. M.; Yoon, S.-H.; Mochida, I. Interaction of vanadyl complexes in atmospheric residue with their matrices: an ESR study in a temperature range up to $170{ }^{\circ} \mathrm{C}$. J. Phys. Chem. C 2019, 123, 20587.

(33) Pekerar, S.; Lehmann, T.; Mendez, B.; Acevedo, S. Mobility of Asphaltene Samples Studied by ${ }^{13} \mathrm{C}$ NMR Spectroscopy. Energy Fuels 1999, 13, 305-308. 